\title{
Epilepsy and quality of life in Iranian epileptic patients
}

\author{
Bahareh Honari ${ }^{1}$, Seyed Mehran Homam², Maryam Nabipour ${ }^{3}$, Zahra Mostafavian ${ }^{4}$, Arezou Farajpour ${ }^{5}$ and \\ Nyusha Sahbaie ${ }^{3}$
}

\begin{abstract}
Background: Epilepsy is one of the most common neurological disorders with physical, emotional, and social consequences. Previous studies indicate that epilepsy symptoms can highly affect the epileptic patients' satisfaction in life. The aim of the present study is to investigate the QOL of People with Epilepsy (PWE) in Khorasan Razavi province, Iran.

Methods: In this study, 100 patients were randomly selected. After confirmation of the diagnosis of epilepsy by neurologists and fulfilling the entrance criteria, patients completed the Quality of Life in Epilepsy-31 inventory (QOLIE-31) questionnaire. Finally, data was analyzed statistically by SPSS software.
\end{abstract}

Results: The study sample comprised 100 PWE, aged 18-74 years (34 \pm 13 ), of whom 58 (58\%) were females. Toniccolonic seizure was the most common (60\%) type of seizure. The obtained score of each subscale and the range of the QOLIE-31 total score was 16.40-79.18 with the mean of $50(S D=16)$. The energy-fatigue subscale score was significantly higher in patients younger than $35(p=0.018)$. The data analysis showed that the seizure worry subscale was significantly higher in single patients $(p=0.04)$. Duration of epilepsy had a positive correlation with QOLIE-31 total score $(p=0.038)$, and a negative relationship with energy-fatigue subscale $(p=0.018)$. In contrast with previous studies, which reported the frequency of the epileptic episodes as the most important predictor of $\mathrm{QOL}$, our results showed no significant correlation between the number of the episodes and overall QOL score $(p=0.063)$. However, the number of episodes was significantly correlated with emotional well-being and cognition subscales. Furthermore, the results indicated that poor QOL score is correlated with depressed mood.

Conclusion: In fact, the ultimate and preferred outcome of all treatments and care interventions is the patient's $\mathrm{QOL}$. Thus, improvement of the QOL by means of obtaining more information about its contributing factors, in PWE should be one of the main goals in the patients' treatment.

Keywords: Epilepsy, QOLIE-31 questionnaire, Quality of life

\section{Background}

Epilepsy is a serious brain disorder in which it has different manifestations such as different types of seizures and syndromes [1].

A meta-analysis done in Iran has showed that epilepsy prevalence is $5 \%$, and it was estimated that $3 \%$ of patients are younger than 20 years of age [2].

\footnotetext{
* Correspondence: mehrhomam@mshdiau.ac.ir

${ }^{2}$ Department of Neurology, Mashhad Branch, Islamic Azad University,

Mashhad, Iran

Full list of author information is available at the end of the article
}

The World Health Organization (WHO) defined Quality of Life (QOL) as the conception of individuals' of their position in life which is framed by culture and its value system [3]. As epilepsy is a chronic illness and has a nature of epileptic seizures, it can have multiple effects on a patient's perception about quality of and satisfaction with life [4]. Moreover, epilepsy can be associated with physical, emotional, and social outcomes [5].

In previous studies, epileptic patients have reported a low QOL because they may have lower self-esteem, and greater anxiety, and depression. In some patients, social
Springer Open (c) The Author(s). 2021 Open Access This article is licensed under a Creative Commons Attribution 4.0 International License, which permits use, sharing, adaptation, distribution and reproduction in any medium or format, as long as you give appropriate credit to the original author(s) and the source, provide a link to the Creative Commons licence, and indicate if changes were made. The images or other third party material in this article are included in the article's Creative Commons licence, unless indicated otherwise in a credit line to the material. If material is not included in the article's Creative Commons licence and your intended use is not permitted by statutory regulation or exceeds the permitted use, you will need to obtain permission directly from the copyright holder. To view a copy of this licence, visit http://creativecommons.org/licenses/by/4.0/. 
stigma and its impacts on QOL lead to a challenge especially in severe clinical manifestations [6]. It is believed that demographic factors also play a crucial role in $\mathrm{QOL}$ [7].

There are so many tools that have been used to measure the QOL in epileptic patients, some of these tools are for general use and some are designed specifically for epileptic patients, such as the quality of life in epilepsy- 31 inventory (QOLIE-31) questionnaire [8].

QOLIE-31 is one of the most accepted tools, which is used especially in adults 18 and older. This tool, in fact, is derived from QOLIE-89. QOLIE-31 has been used in multiple clinical studies as a standard tool. The reliability and validity of the Persian version of this tool has been evaluated in Iran [9].

Although 80\% of People with Epilepsy (PWE) live in developing countries, there's little information about patients' QOL in low-income countries [10]. A systemic review of QOL in 2011 showed that 61 of 86 studies in this field had been done in Europe and North America, developed countries with high income [11]. So far, our knowledge about the quality of life in Iranian epileptic patients has been obtained from the short form 36 health survey questionnaire (SF-36) [12, 13].

Since there are a few literatures about the evaluation of QOL in Iranian PWE, This study aims to identify the effect of demographic and disease features on epileptic patients' QOL in Iranian society by means of QOLIE-31 questionnaire.

\section{Material and methods}

The current study has been performed on the epileptic patient members of Khorasan Razavi Epilepsy Society in 2018. Most of the epileptic patients in the east of Iran are members of this society.

The sampling method was random. The sample size was measured based on the study of Mohammadi et al. [14]. The following formula was used to calculate the sample size:

$$
n=\left(\frac{z 1-\alpha \times \partial}{d}\right)^{2}
$$

One hundred and ten patients entered our study. Inclusion criteria include having medical records and diagnosis of epilepsy according to a neurologist's opinion, at least two epileptic episodes in the last 12 months, passing at least 1 year from the onset of the disease, age 18 and older, receiving anti-epileptic drugs, and the ability to provide written consent. None of the patients were in hospitals when they were fulfilling the questionnaire.

Exclusion criteria include age 66 and older, nonepileptic seizures, seizures caused by drug abuse or medications or other emergency situations, inappropriate psychological conditions, chronic underlying disease, having an incurable disease, and unsolicited personal consent.

\section{Materials}

In this study we used the Persian version of QOLIE-31 questionnaire and a checklist which contained demographic variables (age, sex, employment status, marital status) and information about the disease (the nature of the episodes, duration of disease, number of episodes per month, familial history of epilepsy and history of hospitalization because of the disease). QOLIE-31 is a questionnaire that consists of 31 items and 7 subscales. They are emotional well-being, seizure worry, overall QOL, social function, medication effects, cognitive function, and energy/fatigue [15].

Patients' answers to each question are provided to polytomous response options. Scores range from 0 to 100, and a higher score shows better QOL [16]. Scores calculated as $\mathrm{T}$ scores.

\section{Methods}

In this study, 115 patients were selected from Khorasan Razavi epilepsy community. Three patients because of the long-distance, one patient because of the age 66 and older, three patients because of chronic disease, one patient because of the dissatisfaction with the company and, two patients because of the age under 18 were excluded from the study. One hundred and five patients participated in the study. Five forms that we received were incomplete. Eventually, One hundred forms were analyzed. After controlling the inclusion and exclusion criteria, a neurologist's visit and confirmed the diagnosis of epilepsy patients entered the study. After the researcher's explanation about the study and obtaining informed consent, patients filled out the questionnaires. None of the patients were in hospital when they completed the questionnaire.

\section{Ethical considerations}

People in this study were patients that were willing to participate. There was no necessity to write the names in the questionnaire, and all the information was confidential. Research plans were ratified in the ethic committee of Mashhad Islamic Azad Medical University.

\section{Data analysis}

Data were analyzed using software SPSSv20. We report means, standard deviation, and percentage ratio. Student's t-test was used to compare the overall score of QOL and subscales between two groups. Analysis of variance was used in more than two groups, and the Pearson product-moment correlation coefficient was used to study the correlation between duration of 
disease and number of episodes per month with the overall score of QOL and subscales.

Linear regression test was also used to study independent effects of variables, age and duration of disease on subscales, and energy/fatigue. A significant level of $5 \%$ was used.

\section{Results}

\section{Demographic and clinical statistics}

Responsiveness level of participants was 96\%. The age range of patients was 18-74 with a mean age of about $34(\mathrm{SD}=13)$. Fifty-eight participants $(58 \%)$ were female. Demographic features of patients are shown in Table 1, and clinical features are listed in Table 2.

Statistical data about clinical features show that $60 \%$ of our patients have tonic-colonic epilepsy. Sixty-nine percent of patients did not have a positive familial history, and $23 \%$ were hospitalized because of episodes or their complications. The average duration of the disease is 13.4 $(\mathrm{SD}=11.2)$ years, and the average number of episodes is $3 \pm 1.2$ times in a month.

\section{Quality of life}

In this study, the QOLIE-31 overall score ranged from 16.4 to 79.2 , and the average overall score was $50(\mathrm{SD}=$ 16). Table 3 shows descriptive statistics about the QOLIE-31 score with its subscales separately.

There was no significant statistical relationship between QOLIE-31 overall score and clinical and demographic variables such as gender, education, and occupational status.

According to Table 4, patients were divided into two groups of over 35 years of age $(n=34)$ and younger than $35(n=66)$. The energy/fatigue subscale was significantly higher in the group under 35. $(p=0.018)$.

Table 1 Demographic characteristics of the study subjects

\begin{tabular}{lll}
\hline Demographic Characteristics & N (\%) \\
\hline Sex & Female & $58(58 \%)$ \\
Marital status & Male & $42(42 \%)$ \\
& Married & $57(57 \%)$ \\
Education & Single & $43(43 \%)$ \\
& Illiterate & $2(2 \%)$ \\
& Elementary & $27(27 \%)$ \\
& High School Diploma, Bachelor Degree & $66(66 \%)$ \\
Occupation & Master Degree, PhD & $5(5 \%)$ \\
& Governmental & $15(15 \%)$ \\
& Non-Governmental & $27(27 \%)$ \\
Age (in years) & Jobless & $58(58 \%)$ \\
\hline
\end{tabular}

Table 2 Clinical characteristics of the study subjects

\begin{tabular}{lll}
\hline Clinical characteristics & & N (\%) \\
\hline Type & Absence & $3(3 \%)$ \\
& Myoclonic & $3(3 \%)$ \\
& Tonic & $12(12 \%)$ \\
& Clonic & $0(0 \%)$ \\
& Atonic & $5(5 \%)$ \\
Family history & Partial & $17(17 \%)$ \\
& Yes & $31(31 \%)$ \\
Hospitalization due to & No & $69(69 \%)$ \\
Epilepsy side effects (lifetime) & Yes & $23(23 \%)$ \\
Duration of the disease (year) & No & $77(77 \%)$ \\
Number of seizure episodes per month & Range $=1-56$ mean $=13.4$ \\
& SD 11.2 & \\
& 1 & $\mathbf{N}(\%)$ \\
& 2 & $14(14 \%)$ \\
& 3 & $16(16 \%)$ \\
& $41(41 \%)$ \\
& 5 & $13(13 \%)$ \\
& & $16 \%)$ \\
\hline
\end{tabular}

Seizure worry subscale score had a significant statistical difference $(p=0.04)$ between the married group $(35.09+30.4)$ and single group $(48.3+33.1)$.

The Pearson correlation coefficient showed a positive statistical correlation between duration of epilepsy and the QOL overall score $(r=-0.219, p=0.038)$ and a negative relationship with energy/fatigue subscale $(r=-$ $0.244, p=0.018$ ).

There was no significant association between the number of episodes and QOL overall score $(P=0.063)$. However, there were statistically significant positive correlations of frequency of epileptic seizures per month with emotional well-being $(r=0.202, p=0.045)$ and $\operatorname{cog}$ nitive functioning $(r=0.236, p=0.019)$.

Linear regression analysis was done to assess the effect of age and duration of epilepsy on the fatigue/energy subscale. Only age had significant relationship with fatigue/energy subscale $(r=-0.3, p=0.004)$.

Emotional well-being is evaluated by means of five questions (questions number 3,4,5,7 and 9) in QOLIE-31 questionnaire. As the Table 5 shows, the score of all five questions related to the emotional well-being have a significant positive correlation with QOL total score.

\section{Discussion}

In this study, we evaluated the QOL of 100 epileptic patients in the east of Iran who are covered by the Khorasan Razavi Epilepsy Association. 
Table 3 Descriptive statistics in quality of life in epilepsy-31 inventory and Pearson correlation of sub-scales with overall score

\begin{tabular}{llll}
\hline Scale & Mean & SD & Pearson correlation with overall score (P) \\
\hline Seizure worry & 40.8 & 32.1 & $r=0.53(p=0.000)$ \\
Overall quality of life & 30.9 & 14.2 & $r=0.59(p=0.000)$ \\
Emotional well-being & 48.1 & 21.9 & $r=0.72(p=0.000)$ \\
Energy/fatigue & 48.2 & 20.6 & $r=0.57(p=0.000)$ \\
Cognitive functioning & 57.4 & 25.2 & $r=0.76(p=0.000)$ \\
Medication effects & 51.6 & 25.9 & $r=0.55(p=0.000)$ \\
Social functioning & 56.7 & 23.3 & $r=0.82(p=0.000)$ \\
Overall score & 49.7 & 16 & \\
\hline
\end{tabular}

\section{Demographic features}

Surprisingly, our findings showed that there was no significant relationship between QOL score and demographic features such as sex, employment, and education level, while epidemiologic studies on evaluation of QOL related factors in Iran suggested that poor economic status and lower education level are the most important predictors of lower QOL in Iranian society [17-19]. Also, a study in western Iran showed that socioeconomic status, physical inactivity, chronic diseases and lack of health insurance coverage are the most influential factors that cause poor QOL [18]. A previous study has reported a significant negative correlation between female gender and lower educational level with the QOLIE score in epileptic patients. Furthermore, this study represented that the majority of epileptic patients are not employed, although this factor had no significant effect on our patients' quality of life score [20]. The differences between our finding and earlier projects might be because of smaller sample size in the present study.

Considering the given data in Table 4, we can infer that patients younger than 35 years of age achieved higher energy/fatigue score. A study by Djibuti revealed that age strongly correlates with overall quality of life, energy/fatigue, and cognitive scores [20].

According to the data, married patients had a lower seizure worry subscale score. A study by Tajvar et al. in 2008 showed a better QOL in married individuals in Iran [17]. Also, a study done by Zhao et al. reported that married PWE achieved a higher QOLIE-89 total score [21]. The decreased seizure worry subscale score of the married PWE group in our study may be due to impaired social support in Iranian society [22].

\section{Quality of life in epileptic patients}

In the present study, the overall QOL score is 50 (SD = 16). A study done by Saadi et.al, compared the total

Table 4 QOLIE-31 subscales based on age groups

\begin{tabular}{|c|c|c|c|c|c|}
\hline subscale & Age (inyears) & Mean & Std. Deviation & $\mathrm{t}$ & $p$-value \\
\hline \multirow[t]{2}{*}{ Seizure worry } & $<35$ & 42.8118 & 32.64781 & .869 & .387 \\
\hline & $>35$ & 36.9094 & 31.23813 & .881 & .381 \\
\hline \multirow[t]{2}{*}{ Overall quality of life } & $<35$ & 31.2500 & 14.90773 & .331 & .742 \\
\hline & $>35$ & 30.2500 & 13.10173 & .345 & .731 \\
\hline \multirow[t]{2}{*}{ Emotional well-being } & $<35$ & 49.2121 & 22.53989 & .673 & .502 \\
\hline & $>35$ & 46.0606 & 20.71524 & .693 & .491 \\
\hline \multirow[t]{2}{*}{ Energy/fatigue } & $<35$ & 51.7424 & 19.18518 & 2.411 & .018 \\
\hline & $>35$ & 41.4706 & 22.00308 & 2.307 & .025 \\
\hline \multirow[t]{2}{*}{ Cognitive functioning } & $<35$ & 56.6760 & 25.22070 & -.392 & .696 \\
\hline & $>35$ & 58.7833 & 25.58253 & -.390 & 698 \\
\hline \multirow[t]{2}{*}{ Medication effects } & $<35$ & 51.9338 & 27.60702 & .174 & .862 \\
\hline & $>35$ & 50.9765 & 22.62678 & .186 & .853 \\
\hline \multirow[t]{2}{*}{ Social functioning } & $<35$ & 59.6308 & 23.45979 & 1.723 & .088 \\
\hline & $>35$ & 51.2059 & 22.41182 & 1.748 & .085 \\
\hline \multirow[t]{2}{*}{ Overall score } & $<35$ & 50.7708 & 16.33256 & .880 & .381 \\
\hline & $>35$ & 47.7377 & 15.43315 & .896 & .373 \\
\hline
\end{tabular}


Table 5 Correlation of emotional well-being related question with total QOL score

\begin{tabular}{llllll}
\hline & Question 3 & Question 4 & Question 5 & Question 7 & Question 9 \\
\hline Correlation Coefficient & .595 & .522 & .463 & .551 & .535 \\
$P$ value & .0001 & .0001 & .0001 & .0001 & .0001
\end{tabular}

QOLIE score globally. They reported that Russia and Canada with 42.1 and 82 scores had the lowest and highest recorded scores respectively [23]. Consistent with our results, previous studies have showed that the duration of epilepsy disease has a negative relationship with the energy-fatigue score [24]. Moreover, we revealed that there is a positive correlation between disease duration and the total QOL score. Szaflarski et.al also reported the same result. They believed that the coping mechanism and achieving an optimal treatment due to multiple medication trials can lead to a better QOL in patients with longer duration of epilepsy disease [25]. In contrast to previous reports, which indicated that the frequency of seizure episodes is the most important predictor of poor QOL in epileptic patients [24, 26, 27], our results showed no significant relationship between the number of episodes and total QOLIE-31 score. However, in this study, the frequency of episodes was negatively correlated with emotional well-being and cognition subscales. Geukht et.al suggested that since the frequent episodes of seizure interferes with routine daily activity of PWE, it would dramatically affect the QOL [24].

According to the data of Table 5, the scores of the five questions related to the emotional well-being subscale were positively correlated with QOL total score. The mood of patients can be evaluated using the results of those five questions which determine emotional wellbeing. Base on this fact, we can infer that the depression is one of the determinants of poor QOL which is supported by previous studies [28, 29].

Patients are often the best resource of information. Medical technology can evaluate the physical, physiological, and biomedical data, but these data cannot array comprehensive images about the patients' situation or treatment results. Therefore, a lot of information can be available only from patients [30, 31].

Patients-reported outcomes can be used to evaluate medical treatment successes. Conception and acceptance of health and disease status depends on social status. Social status such as socioeconomic level and race, have an important role in treatment and its results [32].

Main social factors affecting health are known as social determinants of health; situations in which people were born, grew up, or lived. Social determinants of health also affect individual and social results by biological factors, and they are an important cause of health inequality. Socioeconomic status is about social status and hope for living according to education, income, and occupation $[33,34]$.

Studies show that social and economic deprivation increases the prevalence and incidence of epilepsy. Epileptic patients have lower education, income, and health conditions. Finding a job is also more difficult for them. Other studies reported relations between failures to follow treatment, low socio-economic level, and unsecured insurance coverage in epileptic patients. Housing, education, employment status, and nutrition are social determinants of health that mediate epilepsy care and results. People who live in high standard areas with better quality health care receive better treatment results [34, 35].

Epileptic patients are more in danger of psychological complications compared to the general population. Studies in the last decade show that psychological treatment has a great impact on the patients' QOL [36].

While $80 \%$ of epileptic patients live in developing countries, the primary goals of treatment are focused on physical complications and the control of seizures, while epileptic patients suffer from several psychological challenges such as low self-confidence, depression, and social challenges such as driving constraint, unemployment, and social isolation. These patients are less likely to get married, and they are more likely to get a divorce. Although epilepsy has effects on different social dimensions, marriage is the first source of social support and predicts health status. Studies show that married people report better psychological and physical health compared to single people [37].

It is obvious that QOLIE-31 overall score is under the influence of cultural, social, and economic factors. Higher QOLIE-31 score in a country represents better information about the disease, decrease in stigma, social support and patients' education and awareness about the disease and self-care. A lower score, such as those in this study and in Bhutanese [38] indicates that more education and awareness about the disease is necessary. Therefore, it seems that further QOL related studies are needed in developing countries.

\section{Limitations}

The regional focus on one province of Iran (Khorasan Razavi) and the small number of individuals can be considered as limitations of this study, which requires more cross-sectional studies in the future. 


\section{Conclusion}

In the present study we have identified that PWE younger than 35 years of age had higher energy-fatigue subscale scores. Moreover, the data indicates that the duration of epilepsy had a positive correlation with QOLIE-31 total score. Also, In contrast with previous studies, our results showed no significant correlation between the number of the episodes and overall QOL score. Unlike the earlier projects, single individuals obtained better seizure worry subscale scores compared to married patients in the present study. Supported by prior studies, our statistical analysis showed that depressed mood was correlated with poor QOL. As the QOL in PWE can be considered as a reflection of cultural, social, and disease-related factors, we suggest that it is up to health care system to give information and educate PWE and the society about the possible overwhelming factors which may affect the QOL in epileptic patients. This issue helps the society and the PWE to achieve a better understanding of the challenges an epileptic patient is dealing with.

\section{Abbreviations \\ QOL: Quality of Life; PWE: Patients with Epilepsy; WHO: World Health Organization; QOLIE-31: Quality of Life in Epilepsy- 31 inventory}

\section{Acknowledgments}

We also gratefully acknowledge Melissa Beth Hirsch who edited and proofread the manuscript.

\section{Authors' contributions}

SMM and BH developed the idea and designed the study. NS collected the data. ZM and AF analyzed and interpreted the data. MN wrote the manuscript. All authors reviewed and approved the final manuscript.

\section{Funding}

Not applicable.

\section{Availability of data and materials}

The datasets used and analyzed during the current study are available from the corresponding author on reasonable request.

\section{Ethics approval and consent to participate}

All procedures performed in studies involving human participants were in accordance with the ethical standards of the ethic committee of Mashhad Islamic Azad Medical University (IRB approval: IR.IAU.MSHD.REC.1398.080).

\section{Consent for publication}

All authors provide consent for publication.

\section{Competing interests}

The authors declare that they have no competing interests.

\footnotetext{
Author details

${ }^{1}$ Faculty of Psychology and Educational Sciences, Semnan University, Semnan, Iran. ${ }^{2}$ Department of Neurology, Mashhad Branch, Islamic Azad University, Mashhad, Iran. ${ }^{3}$ Faculty of Medicine, Mashhad Branch, Islamic Azad University, Mashhad, Iran. ${ }^{4}$ Department of Community Medicine, Mashhad Branch, Islamic Azad University, Mashhad, Iran. ${ }^{5}$ Department of Education Development Center, Mashhad Branch, Islamic Azad University, Mashhad, Iran.
}

Received: 24 May 2020 Accepted: 22 January 2021

Published online: 28 January 2021

\section{References}

1. Schmidt, D., \& Schachter, S. C. (2014). Drug treatment of epilepsy in adults. BMJ., 348, g254.

2. Sayehmiri, K., Tavan, H., Sayehmiri, F., Mohammadi, I., \& CARSON, K. V. (2014). Prevalence of epilepsy in Iran: A meta-analysis and systematic review. Iranian Journal of Child Neurology, 8(4), 9.

3. Group W (1997). Measuring quality of life, (pp. 1-13). Geneva: The World Health Organization

4. Szemere, E., \& Jokeit, H. (2015). Quality of life is social--towards an improvement of social abilities in patients with epilepsy. Seizure., 26, 12-21.

5. Reynolds, E. H. (2000). The ILAE/IBE/WHO global campaign against epilepsy: Bringing epilepsy "out of the shadows". Epilepsy \& Behavior, 1(4), S3-S8.

6. Jacoby, A., \& Austin, J. K. (2007). Social stigma for adults and children with epilepsy. Epilepsia., 48, 6-9.

7. Stavem, K., Loge, J. H., \& Kaasa, S. (2000). Health status of people with epilepsy compared with a general reference population. Epilepsia., 41(1), 8590.

8. Cramer, J. A., Perrine, K., Devinsky, O., Bryant-Comstock, L., Meador, K., \& Hermann, B. (1998). Development and cross-cultural translations of a 31 item quality of life in epilepsy inventory. Epilepsia., 39(1), 81-88.

9. Montazeri, A., Thoghae, M., Vahdaninia, M., \& Ebrahimi, F. (2010). Psychometric properties of the Iranian version of quality of life in epilepsy inventory 31-item. Payesh (Health Monitor), 9(4), 417-424.

10. Kvalsund, M. P., \& Birbeck, G. L. (2012). Epilepsy care challenges in developing countries. Current Opinion in Neurology, 25(2), 179-186.

11. Taylor, R. S., Sander, J. W., Taylor, R. J., \& Baker, G. A. (2011). Predictors of health-related quality of life and costs in adults with epilepsy: A systematic review. Epilepsia., 52(12), 2168-2180.

12. Baker, G. A., Jacoby, A., Gorry, J., Doughty, J., Ellina, V., \& Group S (2005). Quality of life of people with epilepsy in Iran, the Gulf, and near east. Epilepsia., 46(1), 132-140.

13. Gholami, A., Salarilak, S., Lotfabadi, P., Kiani, F., Rajabi, A., Mansori, K., et al. (2016). Quality of life in epileptic patients compared with healthy people. Medical Journal of the Islamic Republic of Iran, 30, 388.

14. Mohammadi, N., Kian, S., Davoudi, F., Nia, S. M. A. A., \& Nojomi, M. (2013). Psychometric evaluation of the Persian version of the quality of life in epilepsy inventory-31. Iranian Journal of Neurology, 12(4), 144.

15. Vickrey BG PK, Hays RD, et al. Quality of Life in Epilepsy QOLIE-31 (version 1. 0); scoring manual and patient inventory 1993. Available from: https://www. rand.org/content/dam/rand/www/external/health/surveys_tools/qolie/ qolie31_scoring.pdf.

16. Vickrey, B., Perrine, K., Hays, R., Hermann, B., Cramer, J., Meador, K., et al. (1993). Quality of life in epilepsy QOLIE-31 (version 1.0): Scoring manual and patient inventory. Santa Monica: Rand.

17. Tajvar, M., Arab, M., \& Montazeri, A. (2008). Determinants of health-related quality of life in elderly in Tehran, Iran. BMC Public Health, 8(1), 323.

18. Rezaei, S., Hajizadeh, M., Khosravipour, M., Khosravi, F., \& Rezaeian, S. (2018). Socioeconomic inequalities in poor health-related quality of life in Kermanshah, Western Iran: A decomposition analysis. Journal of Research in Health Sciences, 18(1), 405.

19. Menati, W., Baghbanian, A., Asadi-Lari, M., Moazen, J., Menati, R., Sohrabivafa, M., et al. (2017). Health-related quality of life and socioeconomic status: inequalities among adults in West of Iran. Iranian Red Crescent Medical Journal, 19(7), e55571.

20. Djibuti, M., \& Shakarishvili, R. (2003). Influence of clinical, demographic, and socioeconomic variables on quality of life in patients with epilepsy: Findings from Georgian study. Journal of Neurology, Neurosurgery, and Psychiatry, 74(5), 570-573.

21. Zhao, Y., Wu, H., Li, J., Dong, Y., Liang, J., Zhu, J., et al. (2011). Quality of life and related factors in adult patients with epilepsy in China. Epilepsy \& Behavior, 22(2), 376-379.

22. Zamani, G., Shiva, S., Mohammadi, M., Gharaie, J. M., \& Rezaei, N. (2014). A survey of quality of life in adolescents with epilepsy in Iran. Epilepsy \& Behavior, 33, 69-72.

23. Saadi, A., Patenaude, B., \& Mateen, F. J. (2016). Quality of life in epilepsy-31 inventory (QOLIE-31) scores: A global comparison. Epilepsy \& Behavior, 65, 13-17. 
24. Guekht, A. B., Mitrokhina, T. V., Lebedeva, A. V., Dzugaeva, F. K., Milchakova, L. E., Lokshina, O. B., et al. (2007). Factors influencing on quality of life in people with epilepsy. Seizure., 16(2), 128-133.

25. Szaflarski, M., Meckler, J. M., Privitera, M. D., \& Szaflarski, J. P. (2006). Quality of life in medication-resistant epilepsy: The effects of patient's age, age at seizure onset, and disease duration. Epilepsy \& Behavior, 8(3), 547-551.

26. Melikyan, E., Guekht, A., Milchakova, L., Lebedeva, A., Bondareva, I., \& Gusev, E. (2012). Health-related quality of life in Russian adults with epilepsy: The effect of socio-demographic and clinical factors. Epilepsy \& Behavior, 25(4), 670-675.

27. Ridsdale, L., Wojewodka, G., Robinson, E., Landau, S., Noble, A., Taylor, S. et al. (2017). Characteristics associated with quality of life among people with drug-resistant epilepsy. Journal of Neurology, 264(6), 1174.

28. Johnson, E. K., Jones, J. E., Seidenberg, M., \& Hermann, B. P. (2004). The relative impact of anxiety, depression, and clinical seizure features on health-related quality of life in epilepsy. Epilepsia., 45(5), 544-550.

29. Loring, D. W., Meador, K. J., \& Lee, G. P. (2004). Determinants of quality of life in epilepsy. Epilepsy \& Behavior, 5(6), 976-980

30. Deshpande, P. R., Rajan, S., Sudeepthi, B. L., \& Nazir, C. A. (2011). Patientreported outcomes: A new era in clinical research. Perspectives in Clinical Research, 2(4), 137

31. Acquadro, C., Berzon, R., Dubois, D., Leidy, N. K., Marquis, P., Revicki, D., et al. (2003). Incorporating the patient's perspective into drug development and communication: An ad hoc task force report of the patient-reported outcomes (PRO) harmonization group meeting at the Food and Drug Administration, February 16, 2001. Value in Health, 6(5), 522-531.

32. Szaflarski, M., Hansen, B., Bebin, E. M., \& Szaflarski, J. P. (2017). Social correlates of health status, quality of life, and mood states in patients treated with cannabidiol for epilepsy. Epilepsy \& Behavior, 70, 364-369.

33. Burneo, J. G., Jette, N., Theodore, W., Begley, C., Parko, K., Thurman, D. J., et al. (2009). Disparities in epilepsy: Report of a systematic review by the north American Commission of the International League against Epilepsy. Epilepsia., 50(10), 2285-2295.

34. Elliott, J. O., Lu, B., Shneker, B. F., Moore, J. L., \& McAuley, J. W. (2009). The impact of 'social determinants of health'on epilepsy prevalence and reported medication use. Epilepsy Research, 84(2-3), 135-145.

35. Hesdorffer, D. C., Tian, H., Anand, K., Hauser, W. A., Ludvigsson, P., Olafsson, E., et al. (2005). Socioeconomic status is a risk factor for epilepsy in Icelandic adults but not in children. Epilepsia., 46(8), 1297-1303.

36. Michaelis, R., Tang, V., Wagner, J. L., Modi, A. C., LaFrance Jr., W. C., Goldstein, L. H., et al. (2018). Cochrane systematic review and meta-analysis of the impact of psychological treatments for people with epilepsy on healthrelated quality of life. Epilepsia., 59(2), 315-332.

37. Wang, F.-L., Gu, X.-M., Hao, B.-Y., Wang, S., Chen, Z.-J., \& Ding, C.-Y. (2017). Influence of marital status on the quality of life of Chinese adult patients with epilepsy. Chinese Medical Journal, 130(1), 83-87.

38. Saadi, A., Patenaude, B., Nirola, D. K., Deki, S., Tshering, L., Clark, S., et al. (2016). Quality of life in epilepsy in Bhutan. Seizure., 39, 44-48.

\section{Publisher's Note}

Springer Nature remains neutral with regard to jurisdictional claims in published maps and institutional affiliations.

\section{Submit your manuscript to a SpringerOpen ${ }^{\circ}$ journal and benefit from:}

- Convenient online submission

- Rigorous peer review

- Open access: articles freely available online

- High visibility within the field

- Retaining the copyright to your article

Submit your next manuscript at $\boldsymbol{\nabla}$ springeropen.com 